\title{
Investigating Teacher Trust towards Principal in High Performing Schools: Comparisons on Teacher Demographic Profiles
}

\author{
Lokman Mohd Tahir ${ }^{1}$, Mohammed Borhandden Musah ${ }^{1}$, Shafeeq Hussain Vazhathodi Al-Hudawi ${ }^{1}$, Sanitah \\ Mohd Yusof ${ }^{1} \&$ Mohd Hanafi Mohd Yasin ${ }^{2}$ \\ ${ }^{1}$ Department of Educational Foundation and Social Science, Faculty of Education, Universiti Teknologi \\ Malaysia, Skudia, Malaysia \\ ${ }^{2}$ Faculty of Education, National University of Malaysia, Bangi, Malaysia \\ Correspondence: Lokman Mohd Tahir, Department of Educational Foundation and Social Science, Faculty of \\ Education, Universiti Teknologi Malaysia, Malaysia. E-mail: p-lokman@utm.my
}

Received: October 8, 2014 Accepted: October 29, 2014 Online Published: February 12, 2015

doi:10.5539/ass.v11n5p169 URL: http://dx.doi.org/10.5539/ass.v11n5p169

\begin{abstract}
This study examines whether teachers in the high performing schools have high levels of trust towards their principal. The study also compares differences in teacher demographic profiles based on their teaching experiences, academic qualifications, age, types of schools and gender. A total of 250 teachers from five selected high performing schools were randomly selected based on teacher trust levels. The study used Tschannen-Moran's (2004) model of trust as instrument, which included benevolence, reliability, competence, honesty and openness as facets of trust. The findings reveal that generally teachers in high performing schools agree to their principals showing these five facets of trust at a high level. Openness facet places the highest level of trust, followed by reliability. On the other hand, facets of benevolence exhibit the lowest level of teacher trust onto principal. Furthermore, the findings unveil significant difference between the premier types within the sub-urban school in the sampled schools. Theoretical and practical implications of the findings are also addressed.
\end{abstract}

Keywords: trust, high performing schools, teacher demographic profile, principal, ANOVA

\section{Introduction}

Recognizing the needs for quality schooling system, the Prime Minister of Malaysia had outlined improving students' outcomes as one among six initial National Key Result Areas (NKRA) in 2010. In attempt to support this objective, the Ministry of Education (MoE) Malaysia introduced the "New Deal" Initiatives (bai'ah) for principals and teachers and as an incentive for schools with achievements exceeding given quality targets. This allows schools autonomy and accountability to innovate their management system and to realign their strategies to ensure student success, thereby producing quality and effective schools (MoE, 2012). This indeed entails on school principals and head teachers as they are crucial in enhancing the professional development of teachers in schools. School leadership must play their significant role in achieving the educational goals and objectives (Brundrett, 2013; West Burnham, 2013). Evidently, teachers' role in attaining the national objectives is pivotal. Teachers are key in determining the direction of schools, solving problems, overcoming challenges in the face of fulfilling the demands of National Education Blueprint (Education Policy, Research and Development Unit [EPRDU], 2006). Teachers are the implementers of educational policies in classroom settings. Therefore, collaboration and trust between teachers with school leaders are seen as an essential 'lubricant' for interaction (Fukuyama, 1995) in the school context (West Brunham, 2013).

With the existence of trust among the two key personnel in schools, educational goals can be achieved. In schooling context trust is able to glue both parties for collaborative efforts and creation of pro-active work culture (Hoy \& Tschannen-Moran, 2003). Tschannen-Moran (2004) and Leithwood et al., (2010) believe that element of trust is an essential element that is capable of linking teachers with principals. The existence of trust enables group improvement cohesiveness, and consequently enhancing student achievement (Hoy \& Tschannen-Moran, 2001; Tschannen-Moran, 2004). Byrk and Schneider (2002) and Byrk et al., (2010) define trust as a 'moral' resource' able to bond teachers and school leaders. The amount of trust principal put on teachers and vice versa is central in creating a conducive, supportive and positive work environment (Hoy, Hoy, 
\& Kurz, 2008; Davies \& Davies, 2013). The assumption is that, if the teachers felt that they are being trusted by the principal, they would be inspired to do their best in relevant tasks towards students' academic achievement (Hoy, Gage, \& Tarter, 2006; Hargreaves \& Fink, 2006).

Even though trust is categorized as an essential element in creating harmonious learning environment, previous studies report cases of breach of trust occurring in school settings. For instance, a study by Abdul Ghani et al. (2008) indicated lack of trust and neglecting teacher needs, feelings and suggestions as mistakes among principals. Negatively, these behaviours exhibit impact on teachers' emotions and physical behaviours. These are consequences of low level of trust between two parties. Emergence of positive bond within the organizational context typically depends on the level of trust existed (McShane \&Von Glinow, 2010). Without trust, it is difficult for any party to adhere and commit to common goals, establish mutual accountability, and learn to unite.

Trust is a positive expectation that others will not act opportunistically either verbally or through actions or decisions (Robbins \& Judge, 2007). In the context of schools, trust between principals as school leaders and between teachers as implementers of school curriculum is sine qua non to producing quality and effective schools and improving student outcome. Existence of trust within the school not only influences teacher behaviour, but also boosts their morale so that they are engaged in attaining school objectives, work for enhancing effectiveness and improvement of schools (O'Brien, 2011). Accordingly, Daly (2009) posited that schools with high trust culture are likely to accept any new ideas from teachers since teachers are committed to accomplish school goals and objectives.

Albeit, trust is considered as significant element that link the school leaders with their teachers, however, not many studies have been carried out in Malaysian school context in general and in the context of high performing schools in particular (Wolfe, 2010; Forsyth, Adams, \& Hoy, 2011). Hence, this study is drawn to address the teachers' level of trust towards their principal.

\section{Literature Review}

\subsection{Trust Research in School Setting}

Historically, the study of trust is a sub-element of sociology, and related to the societal concern (Letki, 2006; Sztompka, 2006). According to Dirks and Ferrin (2002) respected leaders besides having outstanding character and personality as the best role model for their followers, also give importance to trust as well. To Scarbrough (2006) along with instilling respectful relationship among his associates, leaders who aim to accomplish leadership capacity entrusted to them should also be able to spark confidence and trustworthiness among them. It takes time to form trust and it may be built incrementally. Open communication, integrity, mutual respect and support, justice and equality, competence and cooperation are essential ingredients of trust (O'Brien, 2011). It is very unlikely for associates to accept leaders whom they perceive as untruthful, and it is very likely when associates feel that their rights is not being abused that they put trust on their leaders.

As school leaders, competent principals would cherish high expectations on teacher performance. Through distinctive and efficient means of showing trust and respect, they would recognize teachers; would be concerned of and considerate to them; would encourage their participation; would consult them and would provide information as necessary (Davies \& Davies, 2013). School climate thereby would be symbolized by the essential elements of trust, i.e., openness, which is closely related to the higher level of trust in the school context (Forsyth et al., 2011).

To Bryk and Scneider (2002), trust is related to individual obligations. They name two kinds of trusts, organic trust and contractual trust. Organic trust is about members of a social group trusting each other unconditionally whereas contractual trust is based the contractual agreements between parties in social groups. Usually in contractual trust, teachers should keep them away from any misconduct of the contract. However, as Bryk and Schneider (2002) explained contractual trust was ineffective in the educational context since most educational institutions have multilevel goals, which they are expected to achieve. They thus identified a third form of trust, the relational trust which relies on the each party's specific expectations.

Then, Tschannen-Moran (2003; 2004) proposed five facets of trust, namely: benevolence, reliability, competence, honesty and openness. Benevolence is about leaders taking care of the welfare of teachers, that teachers feel being protected by their leaders. Reliability is about teachers depending on the leadership of a principal for example to protect them in the event of any problem. Competence is the belief of teachers that the principal is a good leader and is able to perform tasks as required based on required standards. Honesty includes character, integrity and authenticity of leaders' behaviour, which is instrumental to teachers' trust on principal. 
This also refers to how far teachers can trust principal to fairly protecting them during stressful times. The last facet is openness, which describes how leaders can be open and able to share information with teachers. Trust works both ways. For effective communication to occur there must be mutual trust between the principal and the teachers.

Many educationists believe that school culture impacts significantly on teachers' approach to and their nature of work (Harris, Caldwell \& Longmuir, 2013; Rhodes, Stevens \& Hemmings, 2011; Tarter et al., 1989). School climate, would imply upon on all the three forms of teacher trust within the school context, as Hoy and Tschannen-Moran (1999) posited, namely trust in principal, trust in colleagues and faculty trust in school. These forms of trust, as Robinson, Hohepa and Lloyd (2009) point out would be influenced by the school size as well. According to them school size has much influence on the culture of trust. They believe that the smaller size of the school, teachers will have higher level of trust compared to school having large number of students. Conversely, in this context, differences therein would render on their behaviour as well. Therefore, as Brewster and Railsback (2003) emphasized school leaders are responsible to developing and creating a climate of trust in schools.

\subsection{Related Studies}

Trust has been extensively studied by educational researchers. They studied the subject of trust from various perspectives and mostly it has been a part of their interest in measuring leadership and teacher satisfaction (Lee, 2007; Kim \& Taylor, 2008) and educational systems. Handford (2010) for example mentions few solid reasons to suggest to the substantial importance of existence of trust in school climate and its significance to school achievement. Firstly, schools with high trust were able to increase the student test scores. This was also proven by Bryk and Schneider (2002) who studies significance of trust to improving student reading scores. Secondly, trust is significant associated to teachers' high level of confidence, enthusiasm and to friendly practices among colleagues and their principal, consequently leading to higher student achievement (Handford \& Leithwood, 2013).

Significantly, trust research has drawn educational researcher attention not just from the western perspectives but also other various schools of thought. For instance, in Turkish schools, a study conducted by Kursunoglu (2009) which investigated teacher organizational trust based on the demographic variables such as teacher gender, experience, and teaching subject revealed that there were not significant differences in terms of teacher gender in measuring trust, while differences in the perception of trust typically based on teacher experiences in teaching and subject that they teach in the classroom context were found. The finding was consistent with another relevant findings by Ozdil (2005) and Bokeoglu and Yilmaz (2008) who also found that there was no difference related to trust in principal based on teacher gender. In another study, Sonmez (2005) also indicates that teacher perception of trust was also exhibited least differences in terms of teacher seniority. Furthermore, Erden and Erden's (2009) study also reported that there is an association between Ankara's elementary school principals towards the inclination-to-trust, values and attitudes, demographic variables gender and school size. The study indicates that 48 per cent of the variance in trust was accounted for managers and teachers at Ankara schools in relationship with teacher perception of trust.

Furthermore, Flores (2009) conducted an empirical study in Texas middle schools and found principal's influence as a statistically significant predictor of trust among school teachers. Daly and Chrispeels (2008) also reported that the aspects of benevolence was pivotal in predicting the principals' leadership from the perceptions of 292 site administrators and teachers in three districts in central and southern California. Their findings revealed that the traits of benevolence such as concern, understanding, listening, and support were some of the most powerful predictors of establishment of total trust. Then, using a mixed method design, Daly (2009) studied the presence of trust and leadership approaches in schools which were under the improvement program (IP) and schools with non-IP. Responses were collected from 453 teachers from IP and non-IP schools. His findings revealed that schools with IP program being led by participative and inclusive approach perceived higher level of trust and predicted lower levels of threat-rigid response compared to the schools without IP. Further study conducted by Wolfe (2010) at schools in the state of Virginia entailed the question whether the levels of trust have an empirical association with teacher job satisfaction. From the quantitative data analysis, the researcher found that principals' behaviours while leading the schools have the central impacts towards teacher trust development.

Lee (2007) studied Korean schools mainly in the district of Seoul to examine the relationship between student-teacher trust, which believed to predict school success construct consisting of school adjustment, academic motivation and performance. The finding indicated that 318 students from 7 th grade perceived that 
their trust to their teachers plays a significant role in relation to their performance. Another study by Handford and Leithwood (2013) explored the principal leadership practices, which were interpreted as trustworthiness through 24 post-observational interviews with 24 teachers from high and low trusts schools. The findings indicated that teachers have trust towards their principal leadership practices based on trust indicators of competence, consistency and reliability, openness, respect and integrity.

In Malaysia, there are few researches in particular that studied the existence of trust in local schools. Using Tschannen-Moran trust framework, a study by Lokman et al. (2011) proved that the principals' instructional leadership practices have an impact on the level of teacher trust, while the level of teacher trust also have an impact on teacher commitment to the school. As a result of the test using structural equation model it was found that teacher trust acts as mediator to the practice of instructional leadership variable to teacher commitment to the school. The study also found that trust in the principal has noteworthy values on teacher commitment towards the school. The success of a school typically relies on the positive connection between teacher trust and commitment. The relationship between trust and commitment exists when teachers have high satisfaction after needs are being met by the school leaders, while leaders also get satisfaction when employees attain high productivity and performance. Another study conducted by Abdul Ghani Kanesan et al. (2008) on organizational fairness, trust and altruism, also found that trust in the organization and its principals has a positive relationship towards the organizational fairness. Of the 116 senior administrative assistants who gave their responses to the questionnaire, it is found that 64 per cent of the variance change in teacher trust to the principal. Their study proves that when teachers or principals developed high level of trust believing the organizations are fair, appreciative and mindful of the contribution given, and then in return, teachers will increase their proactive altruism. Although previous studies elaborated that trust has much significance towards teacher commitment and job satisfaction, less emphasis is given to investigate teacher level of trust, which remained as an initial indicators of relationship between teachers with current school leadership practices.

The purpose of this exploratory study was, firstly, to identify the perceptions of teachers in five high performing schools with reference to their trust levels onto trust to their principal; secondly, to analyse the differences in teacher level of trust based on their demographic profiles such as gender, age, teaching experience, types of schools and academic qualifications; and finally, to examine whether teacher demographic profiles have significant influences on teacher level of trust.

\section{Method}

\subsection{Design and Participants}

Since this study is descriptive in nature, it employed the survey design method (Cohen, Manion, \& Morrison, 2003), and data was collected from 199 teacher respondents from purposely selected five high performing schools namely the elite, premier, urban, sub-urban and control categories through an original survey instrument. The instrument sought teachers' perceptions concerning the level of trust towards their principal competencies. The distribution of teachers according to their gender entails that male teachers comprised 28 per cent that gives a total of 34 teachers. As for the female, a total 165 teachers that gives a total of 51.5 per cent responded to the survey instrument. In terms of their age, most teachers that participated in this study aged twenty-five to thirty years old. The second highest numbers of teachers that involved in this study aged between 31 and 35 years old followed by teachers aged between 36 and 40 years old that gives an overall of 26 teachers. As for teachers aged between 41 and 45 year old, the total number is 19 , which also an equal number for teachers aged between 46 and 50 years old. The analysis revealed that only 11 teachers aged between 51 and 55 years old and only three teachers aged between 56 and 60 years old participated in the study.

In terms of teacher academic qualifications, majority of teachers in the high performing schools were bachelor's degree holders ( $\mathrm{n}=176,88.4$ per cent) and only 19 teachers possessed a master's degree ( 9.5 per cent). The analysis also revealed that only four teachers hold Diploma qualification from various educational institutions. Teacher demographic profile also showed that most teachers that participated in this study have being teaching in high performing schools between one and five years $(\mathrm{n}=58,29$ per cent) followed by teachers with six to ten years of teaching experience $(n=48,24$ per cent). The analysis also showed that 29 teachers with teaching experience ranged from 11 to 15 years, and another 19 teachers with teaching experience ranged from 21 to 25 years responded to the survey. Furthermore, the analysis revealed that, 33 teachers with teaching experience between 16 and 20 years, and only 12 teachers who have being teaching for more than 26 years participated in the study. As for school type, they are categorised into five types which comprised the high performing: (a) the elite; (b) urban; (c) sub-urban; (d) control and (e) premier schools. As for teacher sampling, 45 teachers were selected from the elite category, 39 teachers from the urban category, 40 teachers from the control, 30 teachers 
from premier and 45 teachers were from the sub-urban category. Precisely, 250 questionnaires were administered to the sampled six high performing schools. Of the total questionnaires administered, only 199 were returned accounting for a 79.6 per cent response rate.

\subsection{Instrumentation}

The present study applied a translated version of Tschannen-Moran's trust scale used in examining teacher trust onto principal, which was translated to Malay by the researchers since most teachers were locally educated in Malay language. The translation process used the Brislin's (1970) back-to-back translation approach. The questionnaire consisted of two major sections. Section one, comprises eight items entail teacher demographic profile such as gender, teaching experiences, age, academic qualification and types of schools, and section two, comprises 28 items, which were the translated Malay trust scale from Tschannen-Moran's (2004) facet of trust. This questionnaire using a five-point ( $1=$ strongly disagree to $5=$ strongly agree) Likert scale was clustered into five dimensions of trust: (a) benevolence, (b) reliability, (c) competence, (d) honesty and (e) openness. Before the questionnaire was administered to the teachers, the researchers employed a subject matter expert approach for content validity. In this study, the measurement of internal consistency was based on the Cronbach alpha values and the findings showed the values ranged from 0.931 to 0.948 , which demonstrated practical importance of the scales (Hair et al., 2010).

\subsection{Data Analysis}

Descriptive analysis was used to illustrate the distribution, frequency, percentage, mean and compilation of data in a table. Inferential statistics including t-test and one-way ANOVA in responding to the teacher demographic profiles were also used. T-test was used to examine gender differences, while one-way ANOVA was used to evaluate the difference of perception for teacher demographic criteria of age, teaching experience, types of schools and academic qualifications. In determining the influence of teacher demographic profiles to teacher trust, stepwise regression was used to test the predictor variables (teacher age, teaching experience, academic qualification, types of schools and gender) and criterion variables (levels of teacher trust). Using the stepwise approach, the $R^{2}$ is measured and beta weight coefficient is also being identified in determining the significant predictor for teacher trust level.

\section{Results}

\subsection{Factor Analysis and Data Normality}

Before proceeding with data analysis, data normality was checked by analysing the Q-Q plot and histograms and Kolmogorov-Smirnov tests, which provides fundamental characteristic prior to performing inferential statistic and data analysis (Chang et al, 2013). An exploratory factor analysis (EFA) was utilized to determine the factor loadings of the Malay translated version of Tschannen-Moran's (2004) facets of trust. The results reveal satisfactory factor loadings for trust construct, ranging from .5 to.7, indicating practical importance of the loadings (Hair et al., 2010' Steven2002). The issue of low item loading resulted in omitting one item which failed to fulfil the inclusion criteria ( $\geq .5)$ as such, 27 items were retained for further analysis. Overall, the data indicates that the account of variance across trust scales were higher than 0.70 per cent, which are the cut-off values emphasized statisticians (Hair et al., 2010; Tabachnick \& Fidell, 2012). Factor analysis procedure was conducted separately for each trust construct. Kaiser Meyer Olkin (KMO) value was at 0.890 , while for total variance explained was 73.1 per cent.

\subsection{Measuring Teacher Trust}

Based on the first research objective related to whether teachers in the high performing schools have trust onto their principal, descriptive statistics comprised the mean scores and standard deviations revealed reasonable values as presented in Table 1 .

Table 1. Overall mean scores and standard deviations of trust facets

\begin{tabular}{lcc}
\hline Trust Facets & Mean scores & Standard deviations \\
\hline Benevolence & 3.55 & 0.72 \\
Reliability & 3.68 & 0.83 \\
Competence & 3.68 & 0.71 \\
Honesty & 3.67 & 0.69 \\
Openness & 3.76 & 0.67 \\
Overall & 3.67 & 0.72 \\
\hline
\end{tabular}


From Table 1, the facet of openness has the highest mean scores (mean $=0.76 ; \mathrm{SD}=0.67$ ) followed by reliability (mean $=3.68 ; \mathrm{SD}=0.83$ ) and competence (mean=3.68; $\mathrm{SD}=0.71)$. The last two lowest mean trust facets were the honesty and benevolence. Honesty facet has a slightly higher mean score (mean $=3.67 ; \mathrm{SD}=$ $0.69)$ and the lowest mean score was benevolence facet (mean $=3.55$ : $\mathrm{SD}=0.72)$. The overall mean score indicated that teachers have high level of trust towards their principal in leading high performing schools with mean score of 3.67 ( $\mathrm{SD}=0.72$ ). Additionally, the researchers also measure the all five teacher trust scale using the descriptive statistic of frequency and percentage to determine teacher trust patterns related to their levels of agreement and disagreement to their principal which presented in Table 2.

Table 2. Percentage and frequency of high performing schools teacher trust facets

\begin{tabular}{ccccc}
\hline \multirow{2}{*}{ Trust facets } & \multicolumn{2}{c}{ Disagree } & \multicolumn{2}{c}{ Agree } \\
\cline { 2 - 5 } & Strongly disagree & Disagree & Agree & Strongly agree \\
\hline Benevolence & $4(2.0 \%)$ & $15(7.5 \%)$ & $96(48.0 \%)$ & $19(9.5 \%)$ \\
Reliability & $3(1.6 \%)$ & $15(7.5 \%)$ & $97(48.0 \%)$ & $27(13.7 \%)$ \\
Competence & $4(1.8 \%)$ & $22(11.0 \%)$ & $85(43.1 \%)$ & $21(10.3 \%)$ \\
Honesty & $2(1.2 \%)$ & $12(5.9 \%)$ & $109(55 \%)$ & $21(10.3 \%)$ \\
Openness & $2(1.2 \%)$ & $11(5.5 \%)$ & $135(68 \%)$ & $28(14 \%)$ \\
Total & 1.5 per cent & 7.5 per cent & 53 per cent & 11.6 per cent \\
\hline
\end{tabular}

Table 2 depicts the descriptive findings of the five scales of teacher trust; benevolence, reliability, competence, honesty and openness. Data from Table 2 shows that teachers in high performing schools rated their principals as leaders with high levels of trust in the honesty and openness scales compared to other three facets which were reliability, competence and benevolence. Rigorous analysis of the five facets revealed that teachers in high performing schools seemed to agree that principals in high performing schools practice openness facet (82 per cent), which showed principals at high performing able to make themselves vulnerable to teachers when they frequently shared relevant information within their school compound. At the same time, principals in high performing schools create reciprocal positive interactions and build teacher confidence. As seen from the table, the second highest facet of trust is the honesty facet ( 65.3 per cent) followed by reliability ( 61.7 per cent), benevolence (57.5 per cent) and competence facet received least degree of agreement from teachers in high performing schools (53.4 per cent). The overall levels of teacher trust onto principal indicates that 64.6 per cent of teachers in high performing schools trust their principal compared to only 9 per cent of teachers who does not trust their principal.

\subsection{Differences Based on Teacher Demographic Profiles}

In addressing the second research question, which examines whether there were statistical significant differences in relation to teacher trust with reference to their gender, age, teaching experience, types of schools and academic qualifications. In analysing teacher gender, a t-test was executed and the findings were summarized in Table 3.

Table 3. Independence t-test for measuring teacher trust and gender

\begin{tabular}{lcccccc}
\hline \multicolumn{1}{c}{ Variable } & N & Mean & Means Difference & Standard Deviations & F-value & Sig \\
\hline Gender & & & & & & \\
Male & 34 & 3.704 & 0.0342 & 0.67 & 0.200 & 0.655 \\
Female & 165 & 3.670 & 0.0342 & 0.64 & & \\
\hline
\end{tabular}

$* p<0.05 ; \mathrm{N}=199$.

Table 3 above presents independent t-test results for measuring teacher trust towards their principal. Based on the results, it clearly evident that there is no statistical significant difference between male and female teachers regarding their perceptions of trust towards their principal. Comparatively, mean score for male teachers indicated higher scores than their female counterparts, which is an indicative that male teachers have higher levels of trust compared to female teachers in high performing schools. Statistically, the $F$-value was observed to be insignificant. Therefore, it is concluded that there is no any differences based on teacher trust based on the on gender categories. 
Furthermore, we also examined teachers from the high performing schools regarding their assessment of trust based on their age, educational qualification, types of schools and teaching experience. For this reason, a one-way ANOVA technique was used to examine and compare teacher perceptions of trust onto the principal. The results from the analysis showed that there are no significant differences on teacher trust based on teacher age, academic qualifications and teaching experience. However, teacher trust demonstrated statistically significant difference based on types of schools $(F=3.284 ; p=0.012)$. Given the school type significance, post hoc analysis to determine the types of schools, which have differences in teacher perceptions was conducted. Scheffe's post hoc test was used for all types of schools. The result obtained showed that the significant difference between types of schools was between the premier schools and the sub-urban schools, which related to teacher trust scale (Mean difference $=0.44088 ; p=0.042$ ). Result from the post hoc test is presented in Tables 4 and 5 below.

Table 4. One-way ANOVA results for teacher age, academic qualifications, and teaching experience

\begin{tabular}{cccccc}
\hline Variables & $\begin{array}{c}\text { Sum of } \\
\text { Squares }\end{array}$ & $\boldsymbol{d f}$ & Mean Square & F value & Sig. \\
\hline Age & & & & & \\
Between Groups & 2.845 & 6 & 0.474 & 1.116 & 0.354 \\
Within groups & 81.582 & 192 & 0.425 & & \\
Academic Qualifications & & & & & \\
Between Groups & .493 & 2 & 0.246 & .576 & \\
$\quad$ Within Groups & 83.935 & 196 & 0.428 & & \\
Teaching experiences & & & & & \\
Between Groups & 4.619 & 6 & 0.770 & & \\
Within Groups & 79.809 & 192 & .416 & & \\
Types of schools & & & & & \\
Between Groups & 5.354 & 4 & 1.338 & \\
Within Groups & 79.074 & 194 & 0.408 & & \\
Total & 84.428 & 198 & & &
\end{tabular}

Table 5. Scheffe post hoc test for trust facets and school types

\begin{tabular}{ccccc}
\hline (I) school & (J) school & Mean Difference & Std. Error & Sig. \\
\hline Premier & Elite & 0.31563 & 0.13874 & 0.274 \\
& Urban & 0.24457 & 0.14367 & 0.576 \\
& Control & 0.05683 & 0.15420 & 0.998 \\
& Sub-urban & $0.44088^{*}$ & 0.13874 & $0.042^{*}$ \\
\hline
\end{tabular}

${ }^{*} p<0.05 ; \mathrm{N}=199$

In measuring the relationship between teacher trust and demographic profiles, stepwise regression as the primary statistical test was performed. The result from Table 6 indicates existence of predictive power between teacher demographic variables and teacher level of trust. More specifically, data showed that, of the teacher demographic profiles, only teaching experience predicted teacher level of trust onto the principal. However, the other four demographic variables were observed to be insignificantly predictors of teacher level of trust. Thus, teaching experience is deemed as a significant predictor of teacher level of trust $($ Beta $=0.190 ; t=2.079 ; p=$ 0.007).

Table 6. Stepwise regression results for teacher demographic profiles teacher level of trust

\begin{tabular}{cccc}
\hline Variables & Beta & T values & Sig \\
\hline Constant & & 38.457 & 0.000 \\
Teaching experience & 0.190 & 2.079 & 0.007 \\
gender & 0.029 & 0.417 & 0.677 \\
age & 0.011 & 0.078 & 0.938 \\
Academic qualification & 0.088 & 1.253 & 0.089 \\
School's types & 0.017 & 0.242 & 0.809 \\
\hline
\end{tabular}

$\mathrm{N}=199 ; R^{2}=0.036 ; \Delta R^{2}=0.031 ; * p<0.05$. 
Even though, teaching experiences have linkage values with teacher level of trust, teacher demographic variables were considered as weak predictors of teacher level of trust based on the $R^{2}$ and adjusted $R^{2}$ values, which indicate about 0.03 per cent variance to teacher trust onto the principal at the significant level of 0.05 .

\section{Discussions}

This study was designed to examine whether teachers in high performing schools have high level of trust onto their principal. In order to obtain data related to teacher trust, a survey was administered to selected teachers from five types of schools, which were labelled as high performing schools. The examination of differences was examined from teacher demographic profiles including gender, academic qualification, teaching experience and school types.

Evidently, teachers from five types of high performing schools expressed their reflections that they substantially agreed that they have high level of trust onto their principal. The high level of trust was proved by descriptive analysis which entails 64.3 per cent of trust compared to only 10 per cent of teachers that seemed to mistrust their principal. Based on the findings, it also disclosed that teachers from five types of high performing schools were off opinion that their principals practised openness facet, which indicates that principals in high performing schools are able to make themselves vulnerable to teachers when relevant information were shared within their school compound and create reciprocal positive interactions which later builds teacher confidence in realizing the school vision and objectives. In addition, teachers also mentioned that principals in high performing schools also give much priority to the facet of reliability that clearly showed teachers in high performing schools were protected in the event of any problems raised. Thus, it can be proven that principals in high performing schools are reliable persons in leading the schools and always nurture and support teacher when needed. These findings also reinforced the opinion of the Davies and Davies (2013). The study therefore reached the conclusion that school principals should always put high expectations on the achievement of subordinate performance by forming distinctive comment of an efficient and effective principal. Getting trust, understanding, fair and reliable may encourage participation, consultation and provide information as necessary.

Conversely, feedback from teachers on the five principals also found to give less attention to benevolence facet. It could thus be concluded that the principals in high performing give less properties of benevolence in their everyday routines. The results are in line with those of Mayer, Davis and Schoorman (1995), Short and Greer (1997), Hoy and Tschannen-Moran (2003), where principals are believed to remain loyal and faithful to the family, colleagues, school staff, country and religion. They do reveal important information in the benefits of self or others. They are also wise to avoid a conflict of interest between themselves and the organization. They are not prejudiced, discriminatory, or oppressive in allocating resources, determining the duties and the giving of rewards and punishment to the school community. This result does contradicts the finding of Abdul Ghani Abdullah (2008) study and Handford's (2010) study that both studies outlined that as school principal, they have to display benevolence or sense of caring through the positive behaviours such as motivate and support teachers, give their sincere appreciation to teachers' initiatives and practice equity while leading the school. They are also considerate and concern in performing duties. Besides that, they appreciate the award and favours without regarding success as a right. They are also willing to give recognition to the successful school community without any prejudice. However, in this study, the principals were found to be the least in terms of given priority to the aspect of benevolence that leads to higher degree of teacher trust.

The differences were measured based on demographic profiles of gender, age, teaching experience, types of schools and academic qualifications. The result obtained from t-test indicates that no significance difference in terms of teacher gender and their trust onto principals. This finding concurred with findings of Kursunoglu (2009), Ozdil (2005) and Bokeoglu \& Y1lmaz (2008) who conducted studies in different types of schools in different districts in Turkey. Even though, t-test results showed insignificant difference based on gender, mean score for male teachers was observed to be higher compared to the female respondents, which reflects that male teachers have higher levels of trust compared to female teachers in high performing schools even though their numbers were three times smaller than their female counterparts. Based on the descriptive finding, it is observed that male teachers have higher trust compared to female in the high performing school context.

Furthermore, we also analysed the significant differences based on other teacher demographic profiles; age, teaching experience, types of schools they worked in and their academic qualification. The findings revealed that all three demographic variables do not show significant differences when analysed using one way ANOVA. This implies that teachers were upholding similar perceptions in relation to their trust onto their principals with regard to age, teaching experience and academic qualifications. Hence, it can be assumed that three demographic variables did not exhibit much influence or strong predictive power with the levels of trust onto their principal 
leadership style. However, types of schools yielded differences in teacher perceptions of trust to the principals when data showed significant difference in the $F$-value that implies differences based on school types. The ANOVA results clearly indicated that there were differences in terms of the five types of schools considered as high performing schools. Moreover, the results of Scheffe post hoc test revealed that trust demonstrated significant differences between teachers from the premier category school and teachers from the sub-urban category. These results, therefore, reached the conclusion that differences in teacher trust heavily relied on the difference of culture and types of schools that they worked in. Given the differences based on the school type, it is clearly evident that the difference in the school culture is an essential variable that influences teacher level of trust. In addition, the findings concluded that sub-urban school exhibited substantial difference in terms of school culture compared to the premier school that has long history of academic achievement, and have much bigger size compared to the sub-urban school even though both schools are being classified as high performing schools. This finding coincided with Robinson et al., (2009); Rhodes et al., (2011) and Harris et al., (2013) which pointed that school culture plays a significant role on the school trust among teachers. Previous researchers of school trust, study less of the culture and types of schools that influence the teacher level of trust. This study contributed and added new body of knowledge in school types based on the literature that trust can be differentiation based on school culture, types and contexts.

Finally, the results of stepwise regression analysis confirmed that all demographic variables were weak predictors of teacher trust excluding teaching experience. Based on the table, teaching experience is most significant predictor for teacher trust. This contrasts the finding of Erden and Erden (2009) who studied Ankara schools and that some of teachers' and managers' demographic variables were observed to be significant predictors of teacher trust. In this study, it is claimed that the more experienced teachers are the more is their level of trust onto principals. This is so, because some of the teachers are having as much experience as that of their principals.

\subsection{Theoretical Implications}

The study is an initial attempt to examine teacher's level of trust among five high performing schools. The theoretical implications basically based on data that reflects on the teachers' trust to their principals. Daly (2009) mentioned that trust existed in our schooling context even though there is a paucity that measure trust as part or sub-elements of schooling context. Findings of Daly's (2009) study also revealed that the benevolence facet was perceived as the least trust facet in context of high performing schools. In essence, benevolence refers as a person with high integrity, honest and can be labelled as faithfulness. Therefore, emphasis on the facet of benevolence in principals' training and workshops should be implemented by the Ministry of Education in order to produce aspiring principals and heads that have high sense of caring, positive intentions and always provide their supports as part of school's improvement process.

In particular, this study is a replication of previous research work dealing with the teachers' level of trust and detailed using teachers' demographic profiles. This study, however, is considered as significant when the types of schools also being added and investigate as part of teachers' profiles which previously often neglected by previous researchers. Based on the findings, it is clear that there is a strong linkage between school cultures and types with teachers' level of trust since significant differences were observed when analysing the school's type with teachers' trust scale. Therefore, principals and heads should always study the school's culture variable when leading and managing schools.

\subsection{Research Implications}

It is proposed to future researchers to pay particular attention to some critical aspects in which the study obtained can meet real purpose. Following are some suggestions for further studies: The study was conducted in secondary schools of parents' choice of high performing schools only. Therefore, further research may be applied to the primary and the other secondary, which includes boarding schools, religious schools, technical schools and other states and districts. Studies related to this topic can also be done by enlarging the sample size and study locations; for example, involving all secondary schools in the district or all secondary schools in the state of Johor. Increasing the sample size and the sample area may also be done so that the findings can be generalized to a larger population.

Further research on this topic can also be conducted using other methods of qualitative research. The observation, for example, can be done in depth in order to understand and advance findings on this topic. Further information on this research topic against more complex matters may not be rooted out through quantitative methods per se, but also through the use of qualitative methods. Findings would further increase the knowledge of management especially on schools management through a variety of research methods. 


\section{References}

Abdullah, A. G. K., Ismail, A., \& Ngang, T. K. (2008). Implication of principal's misconduct behaviours to teachers. Unpublished research report, School of Educational Studies, Universiti Sains Malaysia.

Bokeoglu, O. C., \& Y1lmaz, K. (2008). Teachers' perceptions about the organizational trust in primary school. Kuram ve Uygulamada Eitim Yönetimi Dergisi, 54, 211-233.

Brewster, C., \& Railsback, J. (2003). Building trusting relationships for school improvement: implications for principals and teachers', Northwest Regional Educational Laboratory. Retrieved September 1, 2014, from http://educationnorthwest.org/webfm_send/463

Brislin, R. W. (1970). Back-translation for cross-cultural research. Cross-Cultural Psychology, 1,185-216. http://dx.doi.org/10.1177/135910457000100301

Brundrett, M. (2013). Principles of school leadership (2nd ed.). London: Sage.

Bryk, A. S., \& Schneider, B. (2002). Trust in schools. New York: Russell Sage.

Bryk, A. S., Sebring, P. B., Allensworth, E., Luppescu, S., \& Easton, J. Q. (2010). Organizing schools for improvement: Lesson from Chicago. University of Chicago Press.

Chang, Z., Deevos, G., \& Tondeur, J. (2013). Examining school culture in Flemish and Chinese primary schools. Educational Management Administration \& Leadership, 42(4), 557-575. http://dx.doi.org/10.1177/ 1741143213502190

Cohen, L., Manion, L., \& Morrison, K. (2003). Research methods in education. New York: Routledge Falmer.

Daly, A. J. (2009). Rigid response in an age of accountability: The potential of leadership and trust. Educational Administration Quarterly, 45(2), 168-216. http://dx.doi.org/10.1177/0013161X08330499

Daly, A. J., \& Chrispeels, J. (2008). A question of trust: Predictive conditions for adaptive and technical leadership in educational contexts. Leadership and Policy in Schools, 7, 30-63. http://dx.doi.org/10.1080/ 15700760701655508

Davies, B., \& Davies, B. (2013). The nature and dimensions of strategic leadersip. In M. Brundrett (Ed.), Principles of school leadership (2nd ed.). London: Sage.

Dirks, K. T., \& Ferrin, D. L. (2002). Trust in leadership: Meta analytic findings and implications for research and practice. Journal of applied psychology, 84(4), 611-628. http://dx.doi.org/10.1037//0021-9010.87.4.611

Educational Policy Research and Development Unit. (2006). National Educational Blueprint. Putrajaya: Ministry of Education, Malaysia.

Erden, A., \& Erden, H. (2009). Predicting organizational trust level of school managers and teachers at elementary schools. Procedia Social and Behavioural Sciences, 1, 2180-2190. http://dx.doi.org/10.1016/ j.sbspro.2009.01.383

Flores, A. (2009). Principal influence and faculty trust: An analysis of teacher perceptions in Texas middle schools (Unpublished EdD dissertation). The University of Texas at San Antonio.

Forsyth, P., Adams, C., \& Hoy, W. (2011). Collective trust: Why schools can't improve without it. Teachers College, Columbia University: Teachers College Press.

Fukuyama, F. (1995). Trust: The Social Virtues and the Creation of Prosperity. New York: The Free Press.

Hair J., Anderson, R., Tatham, R., \& Black, W. (2010). Multivariate Data Analysis (7th ed.). Englewood Cliff, NJ: Prentice Hall.

Handford, V. (2010). Why Teachers Trust School Leaders? (Unpublished EdD thesis). Ontario Institute for Studies in Education, University of Toronto.

Handford, V., \& Leithwood, K. (2013). Why Teachers Trust School Leaders? Journal of Educational Administration, 51(2), 194-212. http://dx.doi.org/10.1108/09578231311304706

Hargreaves, A., \& Fink, D. (2006). Sustainable leadership. San Francisco: Jossey Bass.

Harris, J., Caldwell, B., \& Longmuir, F. (2013). Literature review: A culture of trust enhances performance. Australian Institute for Teaching and School Leadership. Unpublished manuscript.

Hoy, A. W., Hoy, W. K., \& Kurz, N. M. (2008). Teacher's academic optimism: The development and test of a new construct. Teaching and Teacher Education: An International Journal of Research and Studies, 24(4), 
821-835. http://dx.doi.org/10.1016/j.tate.2007.08.004

Hoy, W. K., \& Tschannen-Moran, M. (1999). Five faces of trust: an empirical confirmation in urban elementary schools. Journal of School Leadership, 9, 184-208.

Hoy, W. K., \& Tschannen-Moran, M. (2001). The conceptualization and measurement of faculty trust in schools: The omnibusT-scale. Retrieved from http://www.coe.ohio-state.edu/whoy/Omnibus\%20T-Scale\%20Paper. pdf

Hoy, W. K., \& Tschannen-Moran, M. (2003). The Conceptualization and Measurement of Faculty Trust in Schools: The Omnibus-Scale. In W. K. Hoy, \& C. G. Miskel (Eds.), Studies In Leadership And Organizing School. Connecticut: Information Age Publishing.

Hoy, W. K., Gage, C. Q., \& Tarter, C. J. (2006). School mindfulness and faculty trust: Necessary conditions for each other? Educational Administration Quarterly, 42(2), 236-255. http://dx.doi.org/10.1177/0013161X 04273844

Kim, J., \& Taylor, K. A. (2008). Rethinking alternative education to break the cycle of educational inequality and inequity. The Journal of Educational Research, 101(4), 207-219. http://dx.doi.org/10.3200/JOER. 101.4.207-219

Kursunoglu, A. (2009). An investigation of organizational trust level of teachers according to some variables. Procedia Social and Behavioral Sciences, 1, 915-920. http://dx.doi.org/10.1016/j.sbspro.2009.01.162

Lee, S. (2007). The relations between the student-teacher trust relationship and school success in the case of Korean middle schools. Educational Studies, 33(2), 209-216. http://dx.doi.org/10.1080/03055690601 068477

Leithwood, K., Harris, A., \& Strauss, T. (2010). Leading school turnaround. San Francisco: Jossey Bass.

Letki, N. (2006). Investigating the roots of civic morality: Trust, social capital, and institutional performance. Political Behaviour, 28, 305-325. http://dx.doi.org/10.1007/s11109-006-9013-6

Mayer, R. C., Davis, J. H., \& Shoorman, F. D. (1995). An integrative model of organizational trust. Academy of Management Review, 20(3), 709-734. http://dx.doi.org/10.5465/AMR.1995.9508080335

McShane, S. L., \& Von Glinow, M. A. (2010). Organizational Behaviour: Emerging Knowledge and Practice for the Real World. New York: McGraw-Hill.

Ministry of Education, Malaysia. (2012). Ministry of Education's Interim 2011 - 2020. Putrajaya: Ministry of Education, Malaysia.

O'Brien, D. (2011). How leaders develop and direct relational trust building efforts in schools (Unpublished Masters by research thesis). University of South Australia.

Ozdil, K. (2005). The relationship between the organizational climate and the level of reliance of teachers on their administrator and among themselves (the example of Yeni Mahalle town) (Unpublished doctoral dissertation). Hacettepe University, Ankara.

Rhodes, V., Stevens, D., \& Hemmings, A. (2011). Creating positive culture in a new urban high school. The High School Journal, (Spring), 82-94. http://dx.doi.org/10.1353/hsj.2011.0004

Robbins, S. P., \& Judge, T. A. (2007). Organizational Behaviour (12th ed.). New Jersey: Pearson Prentice Hall.

Robinson, V., Hohepa, M., \& Lloyd, C. (2009). School leadership and student outcomes: Identifying what works and why. Report of the Iterative Best Evidence Synthesis Programme. Wellington: New Zealand Ministry of Education.

Rousseau, D. M., Sitkin, S. B., Burt, R. S., \& Camerer, C. (1998). Not so different after all: A cross-discipline view of trust. Academy of Management Review, 23(3), 393-404. http://dx.doi.org/10.5465/AMR. 1998.926617

Scarbrough, C. S. (2006). Aspects of school mindfulness and dimensions of faculty trust: Social processes in elementary schools (Unpublished doctoral dissertation). University of Texas, San Antonio.

Short, P. M., \& Greer, J. T. (1997). Leadership in empowered schools: Themes from innovative efforts. New Jersey: Prentice-Hall.

Sonmez, E. (2005). Observation of the relationship between the teachers' trust to their administrators and their organizational citizenship behaviour (Unpublished master dissertation). Marmara University, Istanbul. 
Stevens, J. (2002). Applied multivariate statistics for the social sciences (4th ed.). Mahwah, NJ: Lawrence Erlbaum.

Sztompka, P. (2006). Review essay: New perspectives of trust. American Journal of Sociology, 113(3), 905-919.

Tabachnick, B. G., \& Fidell, L. S. (2012). Using Multivariate Statistics (6th ed.). Boston: Pearson.

Tahir, L. M., Daud, K., \& Rahmat, R. (2011). Relationship between Head teacher's Instructional leadership commitment and trust. The Malaysian Educational Deans' Council Journal, 9, 41-54.

Tarter, C. J., Bliss, J. R., \& Hoy, W. K. (1989). School characteristics and faculty trust in secondary schools. Educational Administration Quarterly, 25(3), 294-308. http://dx.doi.org/10.1177/0013161X89025003005

Tschannen-Moran, M. (2003). Fostering Organizational Citizenship in Schools. In W. K. Hoy, \& C. G. Miskel (Eds.), Studies in Leadership and Organizing School. Connecticut: Information Age Publishing.

Tschannen-Moran, M. (2004). Trust matters: Leadership for Successful School. San Francisco: Jossey Bass.

West Burnham, J. (2013). Contemporary issues in educational leadership. In Brundrett, M. (Eds.), Principles of school leadership (2nd ed.). London: Sage.

Wolfe, C. (2010). Behaviours that develop mutual trust and its association with job satisfaction (Unpublished EdD dissertation). Virginia Polytechnic Institute and State University.

\section{Copyrights}

Copyright for this article is retained by the author(s), with first publication rights granted to the journal.

This is an open-access article distributed under the terms and conditions of the Creative Commons Attribution license (http://creativecommons.org/licenses/by/3.0/). 